\title{
Guide-point modeling for the assessment of left ventricular function: comparison with the standard summation of slices method
}

\author{
Christina Heilmaier*1, Peter Hunold², Joerg Barkhausen ${ }^{2}$ and \\ Kai Nassenstein ${ }^{1}$
}

Address: ${ }^{1}$ University Hospital Essen, Essen, Germany and ${ }^{2}$ University Hospital Schleswig-Holstein, Luebeck, Germany

* Corresponding author

from 13th Annual SCMR Scientific Sessions

Phoenix, AZ, USA. 2I-24 January 2010

Published: 21 January 2010

Journal of Cardiovascular Magnetic Resonance 20 I0, I2(Suppl I):O42 doi:I0.I I86/I532-429X-I2-SI-O42

This abstract is available from: http://jcmr-online.com/content/I2/SI/O42

(c) 2010 Heilmaier et al; licensee BioMed Central Ltd.

\section{Introduction}

Left ventricular (LV) function parameters play an important role in diagnosis, therapy monitoring and risk stratification in a variety of cardiovascular diseases; therefore, their analysis is part of daily clinical practice. The standard SoS-approach, however, is relatively time-consuming, thus, faster alternatives are desirable.

\section{Purpose}

We aimed to prospectively evaluate the accuracy of a new guide-point modeling post-processing technique (GPMapproach) in the assessment of LV function with both the standard steady-state free-precession (SSFP)-sequence and a highly accelerated cine MRI in multi-orientations compared to the standard summation of slices-method based on a stack of short-axis views (SoS-approach).

\section{Methods}

52 consecutive patients were examined on a $1.5 \mathrm{~T}$ scanner with the standard SSFP- ("trueFISP", TR, 3.0 ms; TE, 1.5 ms; temporal resolution, $36 \mathrm{~ms}$ ) and a highly accelerated, single breath-hold temporal parallel acquisition SSFPsequence (TR, $4.6 \mathrm{~ms}$; TE, $1.1 \mathrm{~ms}$; temporal resolution, 40 $\mathrm{ms})$. The standard SSFP-sequence was post-processed both with the standard SoS-approach and the new GPMapproach, which relies on a 4-dimensional model of the LV and requires long- and short-axis views for analysis. The highly accelerated sequence was solely evaluated with the GPM-approach. Thus, in each patient ejection fraction
$(\mathrm{EF})$, end-diastolic volume (EDV), and end-systolic volume (ESV) was calculated using three different approaches and results were compared by applying various statistical tests.

\section{Results}

Post-processing was considerably faster with the two GPM-approaches when compared to the SoS-approach (standard SSFP-sequence/SoS-approach, $6 \pm 3$ min; standard SSFP-sequence/GPM-approach, $4 \pm 1.5 \mathrm{~min}$; accelerated SSFP sequence/GPM-approach, $3 \pm 1.5 \mathrm{~min}$ ).

EF: The approaches did not significantly vary in calculations of EF and in their variances ( $p>0.539)$, mirrored by high Pearson's $(r>0.977)$ and intraclass correlation coefficients (ICC > 0.977).

EDV: Post-processing with the GPM-approaches yielded higher volumes compared to the SoS-approach (Table 1) due to an improved definition of the mitral valve by including long-axis views in the analysis. Consequently, Bland-Altman-Plots showed higher degrees of statistical spread (Figure 1) and significant differences in the variances $(\mathrm{p}<0.00)$ when the SoS-approach was compared with either of the GPM-approaches. Pearson's and intraclass coefficients demonstrated high correlation between the two GPM-approaches $(r=0.968$; ICC = 0.967). 
Figure 1. Bland-Altman-Plots for calculation of the end-diastolic volume:

(a) Standard SSFP-sequence analyzed with the standard summation of slices (SoS)-approach versus standard SSFP-sequence post-processed with the guide-point modeling (GPM)-approach

(b) Standard SSFP-sequence evaluated with the SoS-approach compared to the highly accelerated SSFP-sequence analyzed with the GPM-approach

(c) Standard SSFP-sequence post-processed with the GPM-approach checked against the highly accelerated SSFP-sequence evaluated with the GPM-approach.

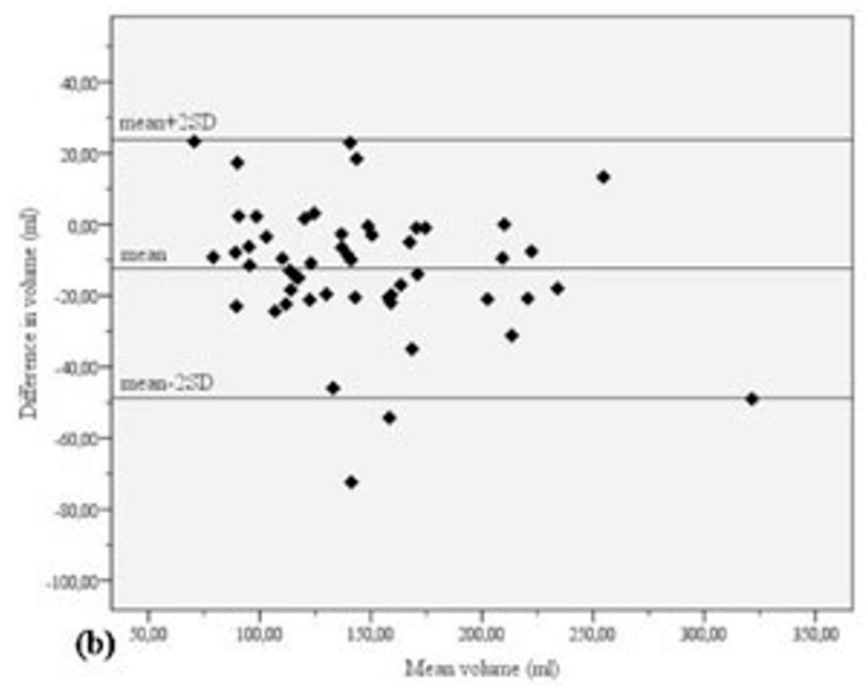

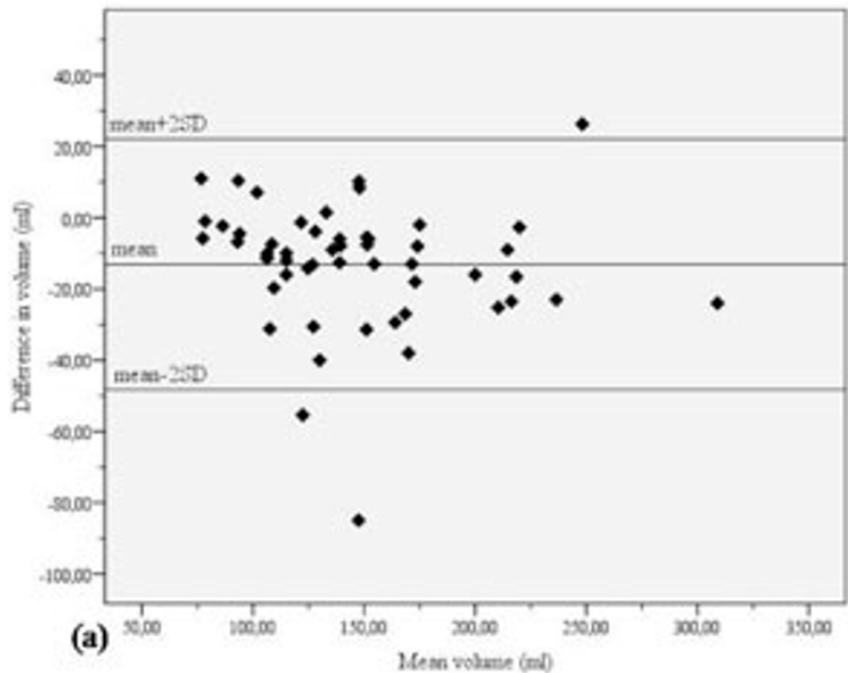

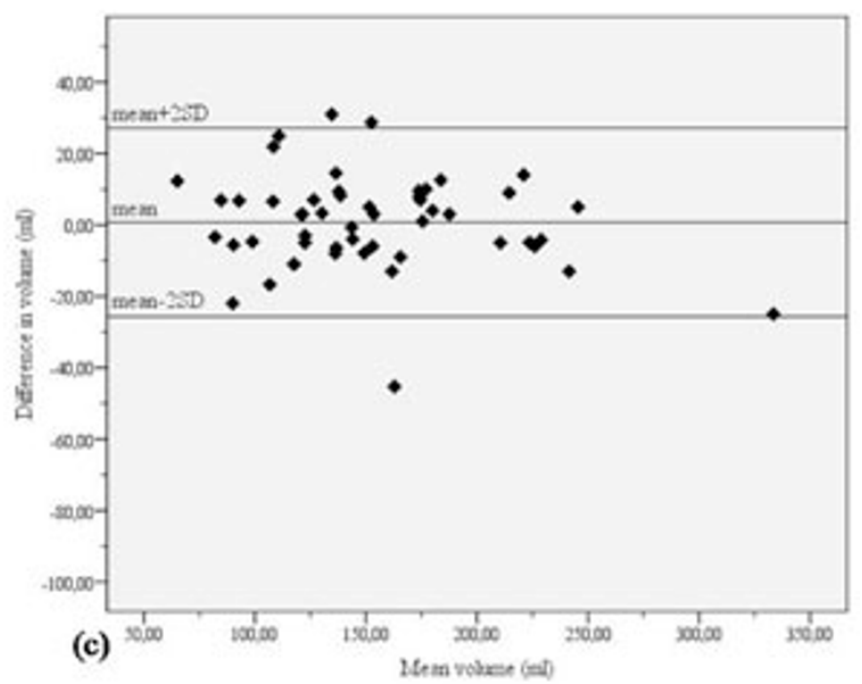

Figure I

Bland-Altman-Plots for calculation of the end-diastolic volume.

ESV: As with EDV, ESV measurements were higher when the GPM-approaches were used. The SoS-approach and GPM-approaches had significant differences in their variances and showed considerably more statistical spread in the Bland-Altman-Plots when compared than was evident between the two GPM-approaches, which demonstrated high correlation $(\mathrm{r}=0.992$; ICC $=0.990)$.

Table I: LV function parameters as measured with the three different approaches

\begin{tabular}{|c|c|c|c|}
\hline & Ejection Fraction (\%) & End-Diastolic Volume (ml) & End-Systolic Volume ( $\mathrm{ml})$ \\
\hline Standard SSFP-sequence with SoS-approach & $54.86 \pm 12.97$ (range, 16-73) & $140.06 \pm 47.92$ (range, $75-297)$ & $68.50 \pm 44.88($ range, $20-250)$ \\
\hline Standard SSFP-sequence with GPM-approach & $54.99 \pm 12.55$ (range, 17-74) & $153.16 \pm 50.10($ range, $7 \mid-321)$ & $73.34 \pm 45.55$ (range, 22-266) \\
\hline $\begin{array}{l}\text { Highly accelerated SSFP-sequence with GPM- } \\
\text { approach }\end{array}$ & $55.07 \pm 13.15($ range, $15-75)$ & $152.43 \pm 52.34$ (range, 59-346) & $73.19 \pm 48.77($ range, $22-294)$ \\
\hline
\end{tabular}




\section{Conclusion}

The GPM-approach can be fast and reliably used with standard and highly accelerated SSFP-sequences and is well-suited for assessment of LV parameters in daily clinical practice.

Publish with Biomed Central and every scientist can read your work free of charge

"BioMed Central will be the most significant development for disseminating the results of biomedical research in our lifetime. " Sir Paul Nurse, Cancer Research UK

Your research papers will be:

- available free of charge to the entire biomedical community

- peer reviewed and published immediately upon acceptance

- cited in PubMed and archived on PubMed Central

- yours - you keep the copyright 